\title{
The experimental study on shear behavior of concrete l-shaped beam with web openings
}

\author{
Mingqiao Zhu, Qiao Jiang, Hailin Huang, Chenkun Liang \\ Hunan University of Science and Technology, Xiangtan, China
}

KEYWORD:Experimental study; Web openings;Concrete I-shaped beams;Annular stirrups;Shear behavior

ABSTRACT:Openings on the I-shaped beam web could accommodate pipelines and therefore might cut down the project cost due to the floor height is lower. In this paper, three concrete Ishaped beams are prepared, the sole difference between their is the openings position on the beam web. To compensate the strength undermined by the openings, annular stirrups are added to the surroundings of the openings. Then, based on these preparation works, a series of experiments were carried out to test the shear behavior of the beams and obtain relevant data, such as deflection, crack width and distribution, strain of reinforcing steel. Data analyses were made according to the statistics collected from the experiments what testified the feasibility of extending the opening at the beam web's ends. Some useful proposals about how to decide the bar amounts of annular stirrups also given by this work.

\section{Introduction}

In tall buildings, burying pipelines to the concrete beams is an effective measure to reduce the layer height of buildings, cost of constructions and consumption of energy.

However, the existence of openings could break down the continuity and integrity of the concrete beams so that the strength and rigidity of the beams could drop, that means the beams may be cracked sooner when the same loads are acting on it. Meanwhile, a beam with openings has its own mechanical characteristics - the stress distribution on the openings nearby is caused by the major stress and secondary stress both. Hence, considering the special nature of the opening beams and referring the studies made by researchers in China, three I-beams are designed with the openings are set in different positions of the beam web in this paper with the aim to supplying experimental basis in this respect.

\section{text specimens and trial}

The trial designed three h-beams (GA1, GA2, GA3)with opening pore web, whose concrete strength grade are C30. Adopt the A6@150mm double limb hoop as shear stirrups, use 2C20+2 C12 as reinforced at the bottom and 4A8 as structural steel at the top to form the steel skeleton. Annular stirrups use $3 \mathrm{~A} 6$ in the form of two rows of three layout in the hole. The diameter of the three hoops are respectively $120 \mathrm{~mm}, 150 \mathrm{~mm}, 180 \mathrm{~mm}$. Laying out radiation rib with $8 \mathrm{~A} 6$ around the stirrup to explore its force transmission mechanism.

Three beams are similar in geometry size that the length is $\mathrm{L}=2100 \mathrm{~mm}$, span is $\mathrm{L}_{0}=2000 \mathrm{~mm}$, all openings are the round hole, pore diameter is $100 \mathrm{~mm}$ and opening eccentricity is $\mathrm{e}_{0}=0$. Cross section size is $b \times h=170 \times 310 \mathrm{~mm}, b_{\mathrm{f}}=370 \mathrm{~mm}, \mathrm{~h}_{\mathrm{f}}=30 \mathrm{~mm}, \mathrm{~b}_{\mathrm{f}}=250 \mathrm{~mm}, \mathrm{~h}_{\mathrm{f}}=30 \mathrm{~mm}$. Transverse dimensions of the components are shown in figure 1(c). Specimen GA1 open pores at mid-span and shear bending section. GA2 and GA3 open pores at shear bending section.

GA1 longitudinal size and reinforcement are shown in figure 1(a), the hole of the pure bending section locates at the midspan;GA2, GA3 geometry size and reinforcement are shown in figure 1(b), and the values of a are $420 \mathrm{~mm}$ and $350 \mathrm{~mm}$ respectively. Three experimental beams all open pore on one side while the other side is no pore.Study the deflection deformation, fracture development and distribution, and the size of the crack width,strain of circular stirrup and longitudinal reinforcement of the same component along with the change of load; Study on the three beams with different opening positions comparativly at the same time to explore the the feasibility of extending opening under the reinforcement of circular stirrup. 


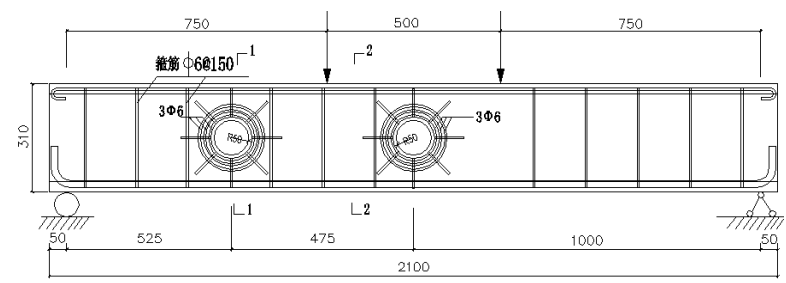

figure 1(a)

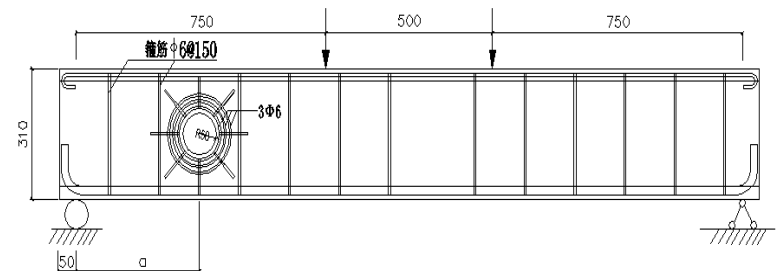

figure 1(b)
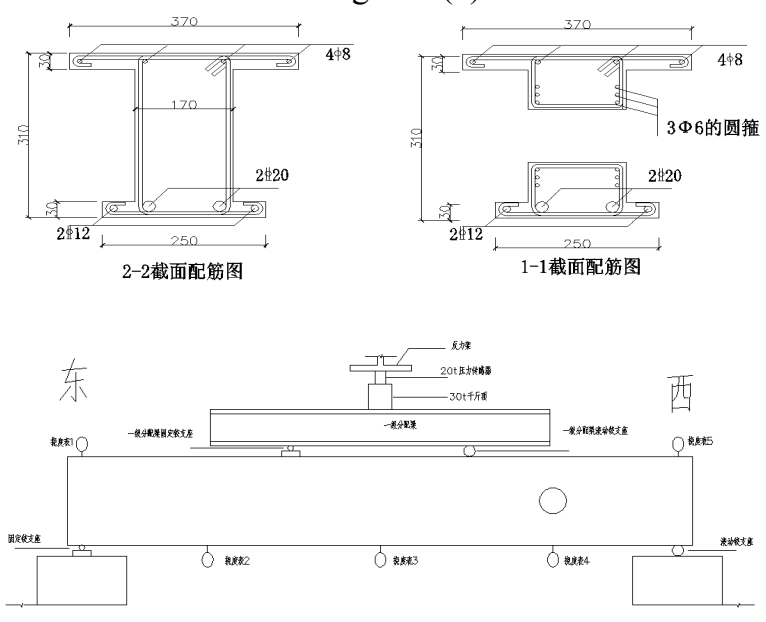

figure $1(\mathrm{c})$

figure 2(a)

\section{Loading device and test content}

Specimen is loaded symmetricly with two point concentration distribution by jack and distributive girder. Put steel plate at load point and support and put a layer of fine sand to level up at the bottom to transmit force uniformly. Arrange five deflection tester for the deflection observation which are labeled as deflection tester 1-5 from left to right.Arrange deflection tester 1 and 5 at support position. Deflection tester 2-4 are arranged at opening pore section, mid-span section, the no opening pore section that is symmetry about midspan with the opening section respectively. Specific corresponding section are identified that GA1 beam corresponds to a1-1to a1-5 section, GA2 corresponds to b1-1 to b1-5 section and GA3 corresponds to c1-1 to c1-5 section. Test loading device schematic and deflection testers layout are shown in figure 2(a).Preload before loading and make each measuring instrument into the normal working condition. Use hierarchical load in the trial, draw midspan and the load deflection curve during the whole process and control cracking load and ultimate load through curve .

The specification of jack used in the experiment is $300 \mathrm{KN}$ and reaction force shall be borne by the upper counterforce frame. Use pressure sensor with $200 \mathrm{KN}$ specification to measure load. Before test, carry on sensor calibration. Use deflection tester to measure displacement, use electron microscope to measure crack width of the selected key point,and the strain data is collected by DH3816 static strain gauge that is produced by jiangsu donghua testing technology limited liability company. Load data are collected twice at all levels and take the average to ensure the accuracy of the test. The whole test is strictly according to the test method standard of concrete structure. 


\section{The test results analysis}

\section{deflection test results}

Deflection value for the comprehensive mechanical properties of the perforated I-shaped beam is an important indicator, and the data is not considering the influence of the support settlement to test out the accurate deflection changes of other measurement points. Deflection of opening side compared with no opening side for the same beam and compare the midspan deflection of the three beams.

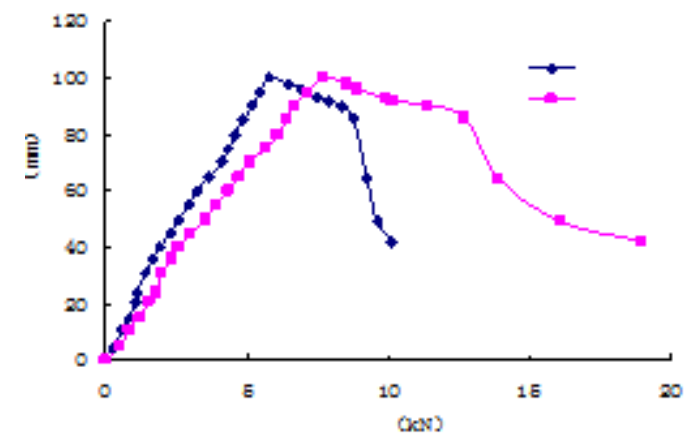

figure $3(\mathrm{a})$

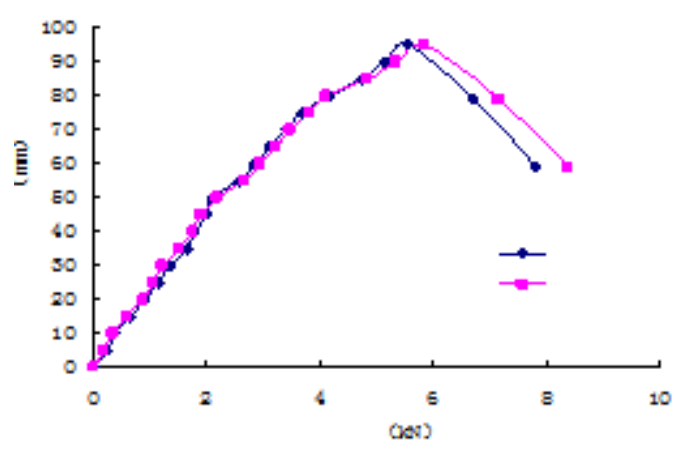

figure $3(b)$

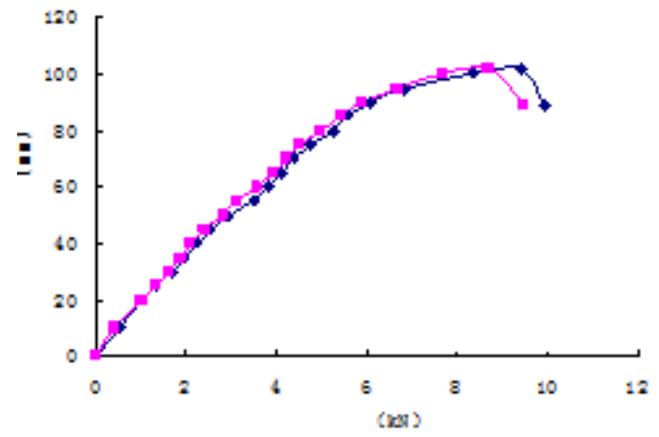

figure 3(c)

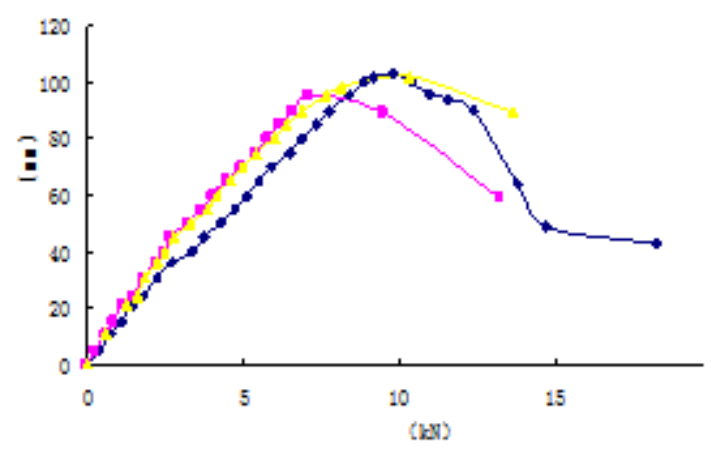

figure 3(d) 
The load deflection curve of GA1 specimen opening side and no opening side are shown in figure 3(a). When the no opening side achieve the load of $36 \mathrm{KN}$, the curveis is upwards two different slopes straight lines to develope, and the slope of opening side changes in roughly $35 \mathrm{KN}$ that show that stiffness of GA1 beam decreases around the load of $35 \mathrm{KN}$, the deformation rate of opening and no opening both increased.After the load increases to limit load, the curve appears decline segments and deformation of the beam increases sharply and destroys eventually. As it is damaged, the deflection of opening side is about $19 \mathrm{~mm}$ which is $8.8 \mathrm{~mm}$ bigger than no opening side. This shows that circular stirrup is poor in reinforcing for rigidity weakening of opening.

Throughout the load stage,the difference between the deflection of GA2 opening side and no opening side is not big, the change points of the slope are basically similar and the value is around $50 \mathrm{KN}$. After reach the limit load,curve decline rate of no opening side is greater than theopening side, As it is damaged, the deflection of no opening side is about $8.5 \mathrm{~mm}$ which is $0.58 \mathrm{~mm}$ bigger than opening side. This shows that circular stirrup is better in reinforcing for rigidity weakening of opening. The load deflection curve is shown in figure $3(\mathrm{~b})$.

GA3 is similar to GA2 beam throughout the load stage,the change points of the slope are basically similar and the difference of deformations is not big. After reach $80 \mathrm{KN}$, changing rate of beam deflection increases slightly, As it is damaged, the deflection of opening side is about $10 \mathrm{~mm}$ which is $0.45 \mathrm{~mm}$ bigger than no opening side. This shows that circular stirrup is better in reinforcing for rigidity weakening of opening. The load deflection curve is shown in figure 3(c).

The load deflection curve trend of the three components are roughly similar, as shown in figure 3(d). The change points of GA1 slope appears earlier compared with GA2 and GA3, namely that GA1 component cracks earlier, The change points of GA2 slope and GA3 slope are more close to. Loads at the same level to ultimate bearing capacity, the deflection of GA1 is larger than GA2 and GA3 beam; As the three beams eventually destroys, the midspan deformation of GA2 and GA3 are similar, the midspan deformation of GA1 is significantly greater than the other two and trial deflection data failed to meet the test standard.

\section{fracture test results}
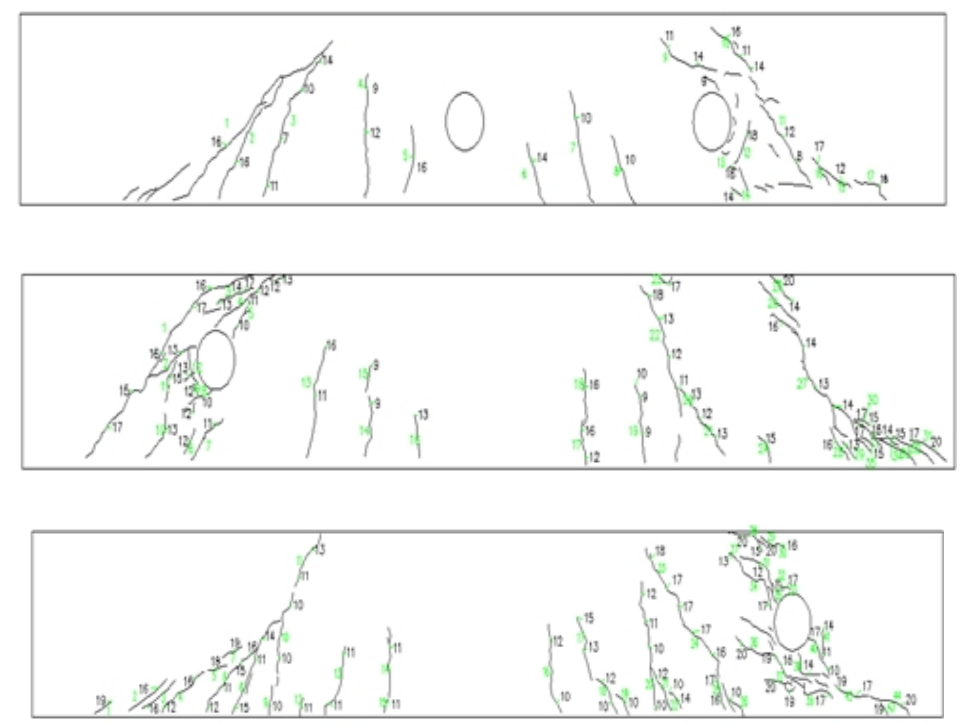

figure $3(\mathrm{e})$

Figure 3(e) is the crack propagation figure as the three components damage. These are GA1 to GA3 beam respectively from top to bottom . Cracks of GA1 components are generally composed by bending and shear cracks which locate at both sides of the mount point below the diagonal and web shear cracks which locate at openging pore side and no opening side. The opening position appears the first diagonal crack as the load reaches $31 \mathrm{KN}$ roughly and the initial crack width is $0.05 \mathrm{~mm}$. The no opening position appears the first diagonal crack as the load reaches $35 \mathrm{KN}$ and the crack width is $0.05 \mathrm{~mm}$. As load increases to about $50 \mathrm{KN}$, the positions of opening and no opening appears crack that locate at load point deviating lower of bending shear section and develops 
gradually to bending shear cracks with the increase of load. The initial position of bending shear cracks locate in tension zone of the concrete and gradually develop to the mount point. The bending shear cracks of opening and no opening positions develop towards both sides load points and lower support place at about 45 degrees. The web shear cracks of opening side gradually forms the critical diagonal crack, when the load reaches $95 \mathrm{KN}$. And the maximum crack width has reached to $2 \mathrm{~mm}$, which is deemed that GA1 component has destroied. and at the same time, the maximum crack width of no opening side is only $0.5 \mathrm{~mm}$.

As for GA2 component, the load point under the oblique of opening side appears cracks first, when the load reaches about $50 \mathrm{KN}$. The initial crack width is $0.055 \mathrm{~mm}$. The no opening side also appears inclined cracks with the load of $55 \mathrm{KN}$ and the crack width is $0.04 \mathrm{~mm}$. Initial cracks on both sides extend to the mount point at roughly 60 degrees or so with the increase of load .The ventral shear fracture of opening and no opening side appear later than the bend shear fractures of loading point below, which extend towards sides load points and support position at about 45 degrees along with the increase of load. When the load achieve $95 \mathrm{KN}$, the ventral shear fracture of no opening side develope to main cracks and critical diagonal crack width reach to $2 \mathrm{~mm}$, the main fracture has been basically run-through, the specimen is declared damage and the test is terminated. At this point, the maximum crack width of opening side is only $0.5 \mathrm{~mm}$.

As for GA2 component, The ventral shear fracture of opening side under the oblique and the cracks of load point on both sides appears cracks at the same time and the initial crack width is $0.05 \mathrm{~mm}$. Initial cracks on both sides extend to the mount point at roughly 75 degrees or so with the increase of load.At the same time, opening and no opening sides occure lots of ventral shear fractures. With the increase of load, the extension of cracks pass through the hole and extend diagonally at about 45 degrees. The maximum crack width of opening side reaches to $1.5 \mathrm{~mm}$ with the load of $100 \mathrm{KN}$, which achieves the destruction symbol of the components. At this point, the maximum crack width of no opening side is $0.5 \mathrm{~mm}$.

All these showed that the maximum width of ventral shear fractures reaching $1.5 \mathrm{~mm}$ is a symbol of the destruction of the test eventually. It indicates that the fractures have played a key role on shear mechanical property of I-shaped beam.

\section{strain test results}

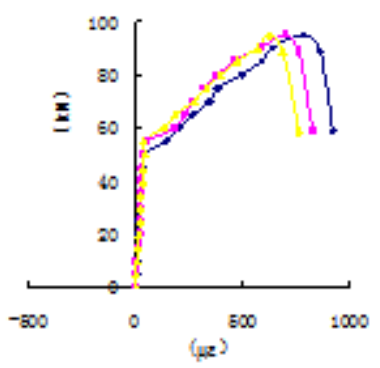

figure $3(\mathrm{f})$

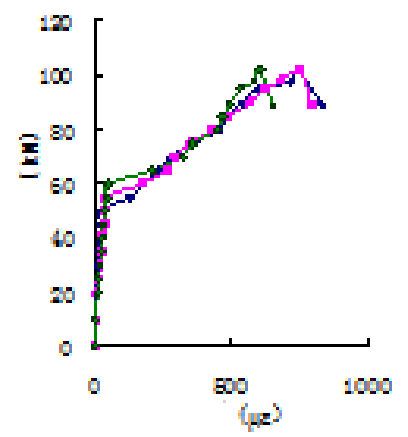

figure 3(f)

Figure 3(f) is load - circular stirrup strain curve of the three beams . These are GA1 to GA3 beam respectively from left to right.As for GA1 beam, strain gauge numbers of three layout circular 
stirrup are $\mathrm{C} 0101, \mathrm{C} 0102, \mathrm{C} 0103$ respectively from inside to outside, which of GA2 and GA3 are B0101, B0102, B0103, A0101, A0102,A0103 respectively.

As is known from the figure analysis, before a certain load, circular stirrup strain of the component is very small and the role almost can be ignored. When it reaches a certain load,the component crack and stirrup stress increases suddenly crack as stress stirrup intersect, which means the slope of the curve slowing down sharply. When the three components destroy, the circular stirrup all play a great role on the shearing. When GA1 component reaches the damage marks, microstrain of circular stirrup is about $900 \mu \varepsilon$. When GA2 and GA3 components reach damage marks, the circular stirrups also play a great role on the shearing and microstrain of circular stirrup is nearly $1000 \mu \varepsilon$. Circular stirrups have a great inhibitory effect on the development of cracks after the component cracks. When component reaches damage marks, the configuration of the annular stirrups in components all meet the yield status. So it suggests that the configuration of the annular stirrups should decrease.

\section{Conclusion}

Through the above research and analysis of the test results, draw the following conclusions:

(1)The circular stirrup reinforcement measures have better effects on inhibiting cracks development, and there is a large degree of reinforcement in the influence on the overall performance of beams due to opening pores.

(2)Opening pores can be extended to 1/6 span under the action of the circular stirrup reinforcement,it may crack earlier and deform larger, when it opens pores in the scope of beam depth apart from the loading point and support position. Therefore it should avoid to open within the scope.

(3)For opening I-shaped beam,three circular stirrup reinforcement layout can not fully play its role. So it is supposed to reduce circular stirrup reinforcement amount.

\section{ACKNOWLEDGMENT}

This paper is funded by the national natural science fund project. The corresponding project number of

this fund is 51378202 .

\section{REFERENCES}

[1]Hengmao Cai. The experimental study of T-shaped reinforced concrete beams with circular web openings[D]. Hefei: HeFei University of Technology, 2007.

[2]Jian Cai, Jing Li, Xuewen Zhang. An experimental study on reinforced concrete beam with the circular opening( I )[J]. Journal of South China University of Technology(Natural Science Edition), $1997,25(2): 68 \sim 72$.

[3]Jian Cai, Taiyun Huang, Jing Li. Experimental study of simply supported reinforced concrete beams with circular web openings[J]. China Civil Engineering Journal, 2009, 42(10): $27 \sim 35$.

[4]Jianlin Zhang, Jian Cai. The main crack patterns and key design points of simply supported reinforced concrete beam with opening[J]. GuangDong Architecture Civil Engineering, 2001, 09, 9:6 8.

[5]Jian Cai, Jing Li, Xuewen Zhang. An experimental study on reinforced concrete beam with the circular opening( II $)[\mathrm{J}]$. Journal of South China University of Technology(Natural Science Edition), $1997,25(3): 101 \sim 105$.

[6]Yaliang Chen, Yanhai Wu. An analysis of mechanical behaviors of RC beam with opening[J]. Journal of FuZhou University(Natural Science Edition), 1999, 27(3).

[7]Ronggui Liu, Zhitao Lv. Experimental research and theoretical analysis on reinforced an prestressed concrete beams with large openings[J]. China Civil Engineering Journal, 2004, 37(7):29 34. 